\title{
William G. Kaelin Jr. and Gregg L. Semenza receive the 2012 ASCI/Stanley J. Korsmeyer Award
}

C ells are able to sense the level of oxygen in their environment and can adapt by rapidly altering expression of various genes. This capacity has both positive and negative implications; following ischemic injury, it can help promote blood vessel growth and recovery, but in cancer, new vessel growth helps sustain developing and metastasizing tumors. In the 1990s, William Kaelin Jr. and Gregg Semenza (Figure 1) revolutionized the understanding of cellular oxygen sensing by identifying many of the molecular players involved. Their continuing work in the field has led to the development of successful therapeutic strategies. In April, their contributions will be celebrated as they receive the 2012 ASCI/Stanley J. Korsmeyer Award. The JCI recently spoke to Kaelin and Semenza about their path to this prize.

JCI: You've both contributed to the understanding of how cells sense and respond to oxygen. What got you into the field?

Kaelin: In 1993 I had my eye out for a new line of investigation that would be distinct from the work I did on the retinoblastoma $(\mathrm{Rb})$ tumor suppressor protein as a postdoctoral fellow with David Livingston. A paper describing the isolation of the von Hippel-Lindau (VHL) tumor suppressor gene crossed my desk that summer, and I thought this would be a great gene to work on, in part because some of the approaches I had used to study Rb seemed well suited to study the VHL protein. I was also very familiar with the clinical features of von Hippel-Lindau disease, which include an increased risk of kidney cancer, hemangioblastoma, and pheochromocytoma, from my clinical training. I thought I would like to work on a common cancer and thought that studying the VHL gene would be an inroad into at least one of those (kidney cancer). In addition, I was always struck by the fact that tumors linked to VHL disease are notable for their ability to secrete erythropoietin and to stimulate angiogenesis, both of which are normally induced in tissues that are receiving inadequate oxygen. In the early 1990s, there was considerable excitement about the idea that blocking angiogenesis would have antitumor effects, but our understanding of the molecular control of angiogenesis was fairly
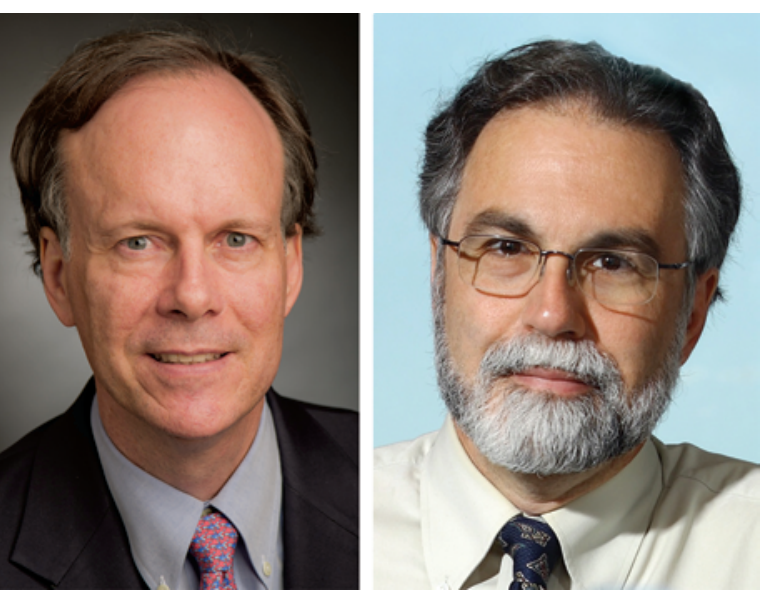

within the gene that were required for the response to hypoxia. Having found this key DNA sequence, which became known as the hypoxia response element, we thought that it probably contained the binding site for a transcription factor that was required for the activation of a transcription under hypoxic conditions. We used the DNA sequence as a probe to identify a protein that was present only when the cells were exposed to hypoxia and named it hypoxia inducible factor 1 (HIF-1). We then used DNA affinity chromatography to purify it: from 1001 of HeLa cells grown in suspension culture, we were able to purify about $50 \mathrm{pMol}$ of the factor. When we purified the protein, we found that it was composed of two subunits that we called Hif1 $\alpha$ and Hif $1 \beta$. We performed limited peptide sequencing and used that data to clone the cDNAs for HIF- $1 \alpha$ and HIF- $1 \beta$.

JCI: When your lab first cloned HIF- $1 \alpha$, did you have an idea of rudimentary. The clinical features of VHL disease, it seemed to me, strongly suggested that the VHL gene would be important for the control of angiogenesis and, more broadly, important for cells and tissues to respond appropriately to changes in oxygen (since, in effect, the tumors linked to VHL disease seemed to constantly "think" they were deprived of oxygen).

Semenza: When I first came to Johns Hopkins as a postdoctoral fellow, I was interested in studying gene regulation, and decided to study the human erythropoietin $(E P O)$ gene. We engineered a series of transgenic mouse lines that contained the human $E P O$ gene with various amounts of the flanking DNA. We were able to identify sequences that controlled its expression in the liver and kidneys, and sequences that prevented expression in other tissues. From there, we became more interested in studying how transcription of the gene was activated in response to low oxygen conditions. We went into a tissue culture system, and we were able to identify the sequences how important it was?

Semenza: Not at all. We had started with expression of the EPO gene was controlled. At the time, there wasn't a lot known about the responses to hypoxia, and there weren't a lot of genes known to be induced by hypoxia. One of the first things that we did was to ask whether other genes regulated by hypoxia were also regulated by HIF-1. We found that genes encoding the glycolytic enzymes and the gene encoding VEGF were activated in response to hypoxia by Hif1. And from there it has really mushroomed - now we know there are over 800 genes regulated by Hif1.

JCI: How did you discover that protein hydroxylation was a mechanism of oxygen sensing?

Kaelin: I wish I could say I used out-ofthe-box thinking, but it was largely the result of some old-fashioned biochemistry and familiarity with the literature. We knew that cells lacking the VHL protein ( $\mathrm{pVHL}$ ) did not degrade Hif1 $\alpha$ a very specific goal: to understand how the 
when exposed to oxygen (in contrast to normal cells), leading to constitutive HIF activation. Two postdoctoral fellows in my laboratory, Cheol Won Park and Mircea Ivan, showed that pVHL could bind directly to HIF, but only if HIF was first incubated with a mammalian cell extract, but this binding was abrogated if the mammalian cells were made hypoxic. Ivan then narrowed down the region of HIF that could bind to $\mathrm{PVHL}$ to a sequence of about 20 amino acids. Fortuitously, in the middle of this was an 8-amino acid stretch that Jaime Caro at Thomas Jefferson had shown was critical for the regulation of HIF by oxygen. Ivan confirmed that replacing all 8 of these residues with alanine eliminated binding to PVHL and then found that only two residues were critical - a leucine residue and a proline residue. We went to the literature to find examples of leucine or proline modifications that might be oxygen and iron sensitive and found a number of papers about the collagen prolyl hydroxylases. We guessed that the modification was prolyl hydroxylation and made a synthetic peptide in which HIF was already hydroxylated and found that it now could bind to pVHL in an oxygen-independent manner, indicating that prolyl hydroxylation was the normal oxygen-dependent signal or could mimic such (we went on to confirm it was the former). The same conclusion was reached independently by Peter Ratcliffe, who published contemporaneously, and shortly thereafter by Frank Lee.

JCI: How broadly applicable are the therapeutic implications of your work?

Kaelin: All solid tumors are believed to have cells that are hypoxic, and so the biology we have helped to discover is probably relevant to many cancers. In addition, hypoxia is an integral part of many other diseases, including myocardial infarction, stroke, and peripheral vascular disease. Drugs that block HIF hydroxylation, and therefore induce HIF, are being developed for these diseases as well as for the treatment of anemia.

JCI: What are some of the limitations of using antiangiogenic therapy in cancer?

Kaelin: The induction of angiogenesis by HIF is due, at least partly, to VEGF, and VEGF inhibitors have significant single- agent activity in kidney cancer. Unfortunately, these drugs are not curative, and even kidney cancers that initially respond eventually become resistant. The activity of VEGF inhibitors in other cancers is even less dramatic, with a few exceptions. To circumvent these limitations, VEGF inhibitors will probably need to be used in combinations, including perhaps with drugs that inhibit other HIF1-responsive angiogenic factors.

JCI: Is there a potential to see HIF1 gene therapy in the clinic?

Semenza: There was a clinical trial in patients who have limb ischemia, but unfortunately, the patients who received the therapy didn't show any improvement. Some of the studies that we've done in aging animals show that there's a deficiency both in production of HIF1 and in the response of the organism to the signals that are generated (such as the angiogenic growth factors), and we found that if we use both gene therapy and bone marrow cell therapy that we dramatically improve the recovery of older animals. We think the situation may be similar in the patients with severe peripheral vascular disease, who are mostly elderly as well. We're now beginning to organize a clinical trial that would involve both gene therapy and cell therapy.

JCI: What was the greatest challenge you've faced in your career?

Semenza: I think it's very challenging when you're a junior faculty member and trying to start up a research program. You have to write grants, you're working in the lab, and you're training and supervising other lab members. Junior faculty also have a lot of responsibility in terms of teaching and organizing seminar series. Looking back, I think that the early faculty years were probably the most challenging time in my career. Now I tell junior faculty that they should understand it will get easier as time goes on.

Kaelin: As an undergraduate, I worked in a chemistry laboratory on an independent study project for 1.5 years and completely floundered - I received a $\mathrm{C}+$ and was told my future probably lay outside the laboratory. In hindsight, I can appreciate that I was working on an undoable and unimportant project - a bad combination!

JCI: The Korsmeyer Award also recognizes your achievements as a mentor. Do you have a philosophy that guides your interaction with trainees?

Kaelin: I was very fortunate, given that first laboratory experience, to subsequently train with David Livingston, who remains one of the best scientists I have ever known. He taught me the importance of articulating scientific questions clearly, of having high standards with respect to experimental design and data interpretation, and of having a prepared mind (including an eye out for the unexpected). I like to think I emulate him in some small way and convey these same principles to my own trainees. I also try to make sure that I am involved sufficiently to know whether anyone in my laboratory is unduly struggling and in danger of "drifting out to sea."

Semenza: The first thing that I ask is what the person's career goals are, and I try to align their training with their goals. Sometimes there's a disconnect between what people are willing to do and what their goals are. I try never to influence anyone regarding the path they want to take, but I'm upfront about what they'll need to do to get where they want to go.

JCI: How did you feel when you learned you'd won the Stanley Korsmeyer Award?

Semenza: It's a tremendous honor to be recognized by one's peers in this way and to receive an award that memorializes a truly distinguished scientist. It's also really appropriate that Bill and I are sharing the award because our work has been complementary in a lot of ways. When we identified HIF-1, and it was obvious that it was induced by hypoxia, but the mechanism by which it was induced remained a mystery for several years. The work of Bill's group also provided a direct link to cancer biology, and that has had great impact on the direction my work has taken.

Kaelin: If there was ever a resounding counterexample to "nice guys finish last," it was Stanley Korsmeyer. Anyone who ever had the privilege of knowing Stan knows that he was one of the nicest people you could ever meet in addition to being an absolutely brilliant scientist. He was (and remains) one of my heroes, and for that reason, I could not be more proud to win this award.

\section{Kathryn Claiborn}

